\title{
TIME INCONSISTENCY OF BENEVOLENT GOVERNMENT ECONOMIES
}

\author{
Leigh TESFATSION* \\ Department of Economics, University of Southern California, Los Angeles, CA 90089-0152, USA
}

Received August 1984, revised version received July 1986

A dynamic Walrasian economy is said to exhibit inconsistency if the competitive equilibrium path resulting from government reoptimization at some time $\tau>0$ is not a continuation of the competitive equilibrium path resulting from the initial government optimization at time 0 . The present paper establishes necessary and sufficient conditions for consistency for a general class of dynamic Walrasian economies. It is seen, for example, that reliance on nondistortionary policy instruments is neither necessary nor sufficient for consistency. It is also shown that Pareto optimal paths can be supported as optimal competitive equilibrium paths only if consistency prevails. However, consistent optimal competitive equilibrium paths need not be Pareto optimal.

\section{Introduction}

Consider a dynamic Walrasian economy comprising a consumer sector, a firm sector, and a government. At each time $\tau \geqq 0$ the government selects a path of policy variables for current and future times so that the corresponding competitive equilibrium path yields the highest feasible social welfare. Such a competitive equilibrium path is refcrred to as the optimal time- $\tau$ competitive equilibrium path. The economy is said to exhibit inconsistency if, for some time $\tau>0$, the optimal time- $\tau$ competitive equilibrium path is not a continuation of the optimal time- 0 competitive equilibrium path.

Inconsistency might seem an unsurprising phenomenon for economies subject to unforeseen disturbances, preference changes, miscalculated policy effects, or basic differences between social and private objectives. However, four recent studies [Calvo (1978, appendix 2), Kydland and Prescott (1980), Fischer (1980), and Turnovsky and Brock (1980)] have produced examples demonstrating that dynamic Walrasian economies can exhibit inconsistency

\footnotetext{
*The present paper is a revised condensed version of a working paper [Tesfatsion (1984a)] presented at the June 1984 Econometric Society Meeting, Stanford, California, and the June 1984 Conference of the Society for Economic Dynamics and Control, Nice, France. The author is grateful to A.B. Atkinson, W.A. Barnett, W.A. Brock, D.A. Kendrick, M.J.P. Magill, A. McLennan, H.C. Quirmbach, D. Spulber, M. Wooders, and two anonymous referees for helpful comments.
} 
even when there is no exogenous uncertainty, preferences are unchanging, all agents have perfect foresight, and government is benevolent in the sense that it attempts to maximize the lifetime utility of the representative consumer through provision of a public good.

In addition, Fischer (1980) finds that consistency prevails in his framework if the government relies solely on nondistortionary taxes to finance the public good; and Turnovsky and Brock (1980) find that consistency prevails in their framework if the government relies on monetary instruments. However, because of the special nature of each framework, it is difficult to determine the generality of these findings.

The present paper establishes necessary and sufficient conditions for consistency for a general class of dynamic Walrasian benevolent government economies which includes the frameworks of the four studies cited above as special cases. Reliance on nondistortionary policy instruments is seen to be neither necessary nor sufficient for consistency in general; ${ }^{1}$ and similarly for reliance on monetary instruments. The relationship between consistency and the two basic welfare theorems is also clarified.

The class of dynamic Walrasian economies treated in the present paper is described in section 2. Each economy is a Walrasian general equilibrium model with a single representative consumer and a single representative firm, extended statically to include a benevolent government sector, and dynamically to allow all agents to reoptimize at each point in time as real time proceeds. Each reoptimization is modelled as an open-loop Stackelberg game with the government as the leader and the consumer and firm as the followers. ${ }^{2}$ The consumer and firm have perfect foresight in the usual ArrowDebreu sense, i.e. at each time $\tau$ they correctly anticipate the currently optimal paths for future prices and future government policies. However, they do not anticipate the possibility of future reoptimization.

General necessary and sufficient conditions for consistency are established in section 3. Briefly, it is sufficient for consistency that certain constraints

\footnotetext{
${ }^{1}$ Specific examples demonstrating that reliance on lump-sum taxation is neither necessary nor sufficient for consistency are provided in Hillier and Malcomson (1984) and in Tesfatsion (1984b). Hillier and Malcomson (1984) focus on the extent to which government has essential control over prices. Both Tesfatsion (1984b) and the present paper focus on the extent to which private agents possess and make use of structural information. Reconciliation of these two viewpoints is an interesting open question. To avoid misunderstanding, it should be noted that the insufficiency examples in both Tesfatsion (1984b) and Hillier and Malcomson (1984) necessarily share the following characteristic: government is not able to achieve the first-best (command) optimum with the particular array of lump-sum taxes and subsidies at its disposal. As clarified in section 5, below, any first-best optimum which can be supported in the initial period as an optimal competitive equilibrium path will be consistently carried out.

${ }^{2}$ As will be clarified in section 2, the successive Stackelberg games are 'open loop' in the following sense. At each successive current time $\tau$, the consumer and the firm make choices for current and future times $t \geqq \tau$ conditioned only on anticipated prices, anticipated government policy variables, and the current time- $\tau$ state vector.
} 
appearing in the constraint set for government's initial time- 0 optimization problem be redundant for that problem. It is necessary for consistency that these same time- 0 constraints be redundant when appended to the constraint sets faced by government as it successively reoptimizes at later times $\tau>0$. The necessary condition for consistency implies, for example, that the plans for current and future times made by the consumer, the firm, and the government at time 0 must never be regretted, even after these plans have actually been implemented.

In section 4 it is shown that the general sufficient condition for consistency established in section 3 is satisfied in two special cases: either (a) the consumer and firm exhibit perfect myopic foresight, in the sense [Burmeister (1980)] that their time- $t$ choice vectors depend at most on the levels and right derivatives of time-t variables; or (b) the consumer has essentially complete structural information, in the sense that the consumer's feasible choice sets incorporate any constraints faced by government which are affected by the consumer's choice vectors. Various macrodynamic studies [e.g. Lucas $(1975,1978)]$ have directly postulated the existence of demand and supply functions for private agents which satisfy special case (a). Special case (b) holds if, for example, consumer choice variables do not appear in the government's budget constraints and the firm sector is simply an extension of the consumer sector with entirely harmonious objectives. However, for the general class of dynamic Walrasian economies considered in section 2 , conditions guaranteeing either special case are stringent.

Section 5 explores the relationship between consistency and the supportability of Pareto optimal paths. It is shown that a Pareto optimal path can be supported as an optimal time-0 competitive equilibrium path only if the latter path is consistent, i.e. only if the economy never veers from this path despite successive reoptimization as real time proceeds. Nevertheless, a consistent optimal time- 0 competitive equilibrium path need not be Pareto optimal.

By definition, an allocation for an economy is first-best optimal if it maximizes social welfare subject only to technological feasibility constraints, where social welfare is typically measured in terms of an increasing function $W(u)$ of the vector of consumer utilities $u$. For the class of economies currently under consideration, with a single representative consumer, a path for the economy is first-best optimal if and only if it is also Pareto optimal. Thus, the results of section 5 establish that consistency is necessary but not sufficient for the attainment of a first-best optimum.

Section 6 relates the necessary and sufficient conditions for consistency established in sections 3 and 4 to the results obtained in previous studies. It is first noted that the inconsistency examples presented in the four initially cited papers each fail to satisfy the general necessary condition for consistency established in section 3 . It is then shown that the circumstances 
described by Fischer (1980) and Turnovsky and Brock (1980) in which consistency holds in their frameworks reduce to one of the two special cases (a) and (b). Briefly, sole reliance on nondistortionary taxes is sufficient for consistency in Fischer's framework; indeed, the outcome then achieved is the first-best optimum. However, Fischer's framework has no firm sector and no market clearing conditions. Thus, sole reliance on nondistortionary taxes implies that no consumer choice variables appear anywhere in the constraints faced by government, and special case (b) holds trivially. Also, consistency prevails in the Turnovsky-Brock framework for stationary solution paths when monetary instruments are optimized. However, the representative consumer and firm both exhibit perfect myopic foresight along these paths; hence special case (a) holds.

The final section 7 contains concluding remarks on special cases (a) and (b). It is noted that, for a subclass of the presently considered class of dynamic Walrasian economies, consistency holds if and only if special case (a) or (b) holds. In particular, for each feasible parameter configuration, the corresponding economy achieves its unique first-best optimum only if special case (a) or (b) holds.

Proofs and technical notes for each section are given in an appendix.

\section{A general class of dynamic Walrasian economies}

The present section describes the general class of dynamic Walrasian economies used throughout the remaining sections of the paper.

As detailed in Tesfatsion (1984a, appendix), each of the four papers initially cited in the introduction uses a particular model from this class of economies. In addition, numerous other macrodynamic studies [e.g. Brock (1974)] have used particular models from this class. Nevertheless, seemingly no previous studies have examined its basic structural properties. Such an examination is undertaken here. For expositional clarity, the main text focuses on the continuous-time case. The straightforward modifications needed to incorporate the discrete-time case are given in the appendix.

The economy consists of a (representative) consumer maximizing lifetime utility subject to feasibility constraints, a (representative) firm maximizing intertemporal profits subject to feasibility constraints, a set of market equilibrium conditions for generating equilibrium price paths, and a government benevolently selecting a feasible path of policy instruments to maximize the lifetime utility of the consumer. The economy begins at time 0 in an exogenously given state, $x^{0}$, and evolves over time in accordance with a system of first-order differential state equations. ${ }^{3}$ All agents reoptimize at each point in time as real time proceeds.

\footnotetext{
${ }^{3}$ The time- $t$ state vector is thus predetermined at each time $t \geqq 0$, a standard assumption in mathematical control theory. The time- $t$ state vector typically comprises stocks in actual existence
} 
More precisely, the consumer's time- 0 optimization problem is to select a choice path $c_{0}^{0}=\left(c^{0}(t)\right)_{t \geqq 0}$ of choice vectors $c^{0}(t)$ for current and future times $t \geqq 0$ to maximize his lifetime utility,

$$
\max _{c_{0}^{0}} \int_{0}^{\infty} u_{t}\left(c^{0}(t) \mid f^{0}(t), g^{0}(t), p^{0}(t), x^{0}(t)\right) \mathrm{d} t
$$

subject to the feasibility conditions

$$
c^{0}(t) \in \mathscr{F F}_{i}^{c}\left(f^{0}(t), g^{0}(t), p^{0}(t), x^{0}(t)\right), \quad t \geqq 0,
$$

and the state equations

$$
\begin{aligned}
& \dot{x}^{0}(t)=S_{t}\left(c^{0}(t), f^{0}(t), g^{0}(t), p^{0}(t), x^{0}(t)\right), \quad t \geqq 0 ; \\
& x^{0}(0)=x^{0} .
\end{aligned}
$$

In (1), $u_{t}$ measures the consumer's time-t utility as a real-valued function of his time-t choice vector $c^{0}(t)$. The consumer's time- $t$ utility is conditioned on the anticipated time- $t$ firm choice vector $f^{0}(t)$, the anticipated time- $t$ government policy vector $g^{\circ}(t)$, the anticipated time- $t$ price vector $p^{0}(t)$, and the anticipated time- $t$ state vector $x^{0}(t) .{ }^{4}$ The time- $t$ feasible choice set for $c^{0}(t)$, conditioned on these same four anticipated vectors, is denoted by $\mathscr{F}_{\mathrm{t}}^{\mathrm{c}}$. Finally, $S_{t}$ denotes the known time- $t$ state function. ${ }^{5}$ Typically the consumer's choice vectors $c^{0}(\mathrm{t})$ incorporate demands for and supplies of goods, services, and financial assets, and the consumer's feasible choice sets $\mathscr{F}_{t}^{c}$ consist of budget constraints and non-negativity restrictions. Dependence of $\mathscr{F}_{t}^{c}$ on the anticipated firm choice vector $f^{0}(t)$ occurs if, for example, the firm distributes profits to the consumer, thus affecting the consumer's budget constraints.

In complete symmetry to the consumer, the time- 0 optimization problem for the firm is to select a choice path $f_{0}^{0}=\left(f^{0}(t)\right)_{t \geqq 0}$ of choice vectors $f^{0}(t)$

at time $t$, e.g. capital stocks as in Fischer (1980) and Kydland and Prescott (1980) and/or money and bond holdings as in Turnovsky and Brock (1980). As detailed in Tesfatsion (1984a, appendix), Calvo's model (1978) has no state variables in the sense used here.

${ }^{4}$ The vectors $c^{0}(t), f^{0}(t), g^{0}(t), p^{0}(t)$, and $x^{0}(t)$ are assumed to be elements of Euclidean spaces having arbitrary finite dimensions, $t \geqq 0$. Superscripts on choice, price, and state vectors and paths are used to indicate time of determination. Subscripts on choice, price, and state paths are used to indicate path duration, with a single subscript $\tau$ indicating a duration over the time interval $[\tau, \infty)$, and a double subscript $s, \tau$ indicating a duration over the time interval $[s, \tau)$.

${ }^{5}$ Consumer optimization problems with a finite planning horizon $T$ are handled in format (1) by specifying $u_{t}$ and $S_{t}$ to be trivial 0 -valued functions, and $\mathscr{F}_{t}^{c}$ to be the empty set, for all times $t>T$. A similar observation holds for the firm and government optimization problems, described below. 
for current and future times $t \geqq 0$ to maximize intertemporal profits,

$$
\max _{f_{0}^{0}} \int_{0}^{\infty} \Pi_{t}\left(f^{0}(t) \mid c^{0}(t), g^{0}(t), p^{0}(t), x^{0}(t) \mathrm{d} t\right.
$$

subject to the feasibility conditions

$$
f^{0}(t) \in \mathscr{F}_{i} f\left(c^{0}(t), g^{0}(t), p^{0}(t), x^{0}(t)\right), \quad t \geqq 0,
$$

and the state equations

$$
\begin{aligned}
& \dot{x}^{0}(t)=S_{t}\left(c^{0}(t), f^{0}(t), g^{0}(t), p^{0}(t), x^{0}(t)\right), \quad t \geqq 0 ; \\
& x^{0}(0)=x^{0} .
\end{aligned}
$$

In (2), $I_{t}$ is a real-valued function measuring the time- $t$ profitability of $f^{\circ}(t)$ conditioned on the anticipated time-t consumer choice vector $c^{0}(t)$, the anticipated time- $t$ government policy vector $g^{0}(t)$, the anticipated time-t price vector $p^{0}(t)$, and the anticipated time-t state vector $x^{0}(t)$. The time- $t$ feasible choice set for $f^{0}(t)$, conditioned on these same four anticipated vectors, is denoted by $\mathscr{F}_{t}^{f}$. Finally, $S_{t}$ denotes the known time-t state function. Typically the firm's choice vectors $f^{\circ}(t)$ incorporate demands for and supplies of goods, services, and capital reserves, and the firm's feasible choice sets $\mathscr{F}_{t}^{f}$ are production possibility sets.

The market equilibrium conditions at time 0 for current and future times $t \geqq 0$ are given by a system of vector equations of the form

$$
0=\mathscr{M}_{t}\left(c^{0}(t), f^{0}(t), g^{0}(t), p^{0}(t), \dot{p}_{+}^{0}(t), x^{0}(t)\right), \quad t \geqq 0,
$$

where $\dot{p}_{+}^{0}(t)$ denotes the vector of right derivatives for $p^{0}(t)$. The presence of the time- $t$ state vector $x^{0}(t)$ in (3) allows the consideration of stock as well as flow market clearing conditions, as in Kydland and Prescott (1980). The presence of $\dot{p}_{+}^{0}(t)$ in (3) allows the imposition of rational expectations equilibrium conditions on the market clearing price path, e.g. the anticipated inflation rate equal to the actual inflation rate for all times $t \geqq 0$ as in Calvo (1978) and Turnovsky and Brock (1980).

Any triplet of sequences $\left(c_{0}^{0}, f_{0}^{0}, p_{0}^{0}\right)=\left(c^{0}(t), f^{0}(t), p^{0}(t)\right)_{t \geqq 0}$ which jointly solves the individual optimization problems (1) and (2) together with the market equilibrium conditions (3) is a competitive equilibrium as usually defined, except here the competitive equilibrium is conditioned on the government policy path $g_{0}^{0}=\left(g^{0}(t)\right)_{t \geq 0}$ and the exogenously given initial state vector $x^{0}$. The government at time 0 is assumed to have complete knowledge of (1), (2), and (3), and to behave benevolently in the following sense: 
government selects a feasible policy path $\boldsymbol{g}_{0}^{0}$ so that the corresponding competitive equilibrium $\left(c_{0}^{0}, f_{0}^{0}, p_{0}^{0}\right)$ yiclds the highest possible lifetime utility for the consumer. ${ }^{6}$

Formally, the time- 0 optimization problem for government is to select a policy path $\boldsymbol{g}_{0}^{0}$ to maximize the consumer's lifetime utility,

$$
\max _{\varepsilon_{0}^{0}} \int_{0}^{\infty} u_{t}\left(c^{0}(t) \mid f^{0}(t), g^{\mathrm{o}}(t), p^{\mathrm{o}}(t), x^{\mathrm{o}}(t)\right) \mathrm{d} t
$$

subject to the feasibility conditions

$$
g^{0}(t) \in \mathscr{F}_{t}^{g}\left(c^{0}(t), f^{0}(t), p^{0}(t), x^{0}(t)\right), \quad t \geqq 0,
$$

the state equations

$$
\begin{aligned}
& \dot{x}^{0}(t)=S_{t}\left(c^{0}(t), f^{0}(t), g^{0}(t), p^{0}(t), x^{0}(t)\right), \quad t \geqq 0 ; \\
& x^{0}(0)=x^{0},
\end{aligned}
$$

the individual optimality conditions

$$
\begin{aligned}
& \boldsymbol{c}_{0}^{0} \text { solves (1) conditional on }\left(\boldsymbol{f}_{0}^{0}, \boldsymbol{g}_{0}^{0}, \boldsymbol{p}_{0}^{0}\right) \text {; } \\
& \boldsymbol{f}_{0}^{0} \text { solves (2) conditional on }\left(\boldsymbol{c}_{0}^{0}, \boldsymbol{g}_{0}^{0}, \boldsymbol{p}_{0}^{0}\right),
\end{aligned}
$$

and the market equilibrium conditions

$$
0=\mathscr{M}_{i}\left(c^{0}(t), f^{0}(t), g^{0}(t), p^{0}(t), \dot{p}_{+}^{0}(t), x^{0}(t)\right), \quad t \geqq 0 .
$$

In (4), $\mathscr{F}_{t}^{g}$ denotes the time- $t$ feasible choice set for the time-t policy vector $g^{0}(t)$ conditioned on $\left(c^{0}(t), f^{0}(t), p^{0}(t), x^{0}(t)\right)$, and $S_{t}$ denotes the known time- $t$ state function. Typically $g^{0}(t)$ comprises fiscal and monetary policy instruments such as taxes, public good expenditures, and changes in money and bond supplies, and $\mathscr{F}_{t}^{g}$ includes a government budget constraint together with non-negativity restrictions on various components of $g^{0}(t)$.

In principle, ignoring existence and uniqueness questions, the optimization problems (1), (2), and (4) can be jointly solved for $\left(c_{0}^{0}, f_{0}^{o}, g_{0}^{o}, p_{0}^{o}\right)$ as functions of the current time 0 and state vector $x^{0}$ in the following iterative manner.

${ }^{6}$ The criterion functions (1a) and (2a) for the consumer and firm satisfy Strotz's (1956, p. 174) consistency condition for any given set of conditioning variables. Consequently, if the government actually implements its optimal time-0 policy path $g_{0}^{0}$ over times $t \geqq 0$, the corresponding time-0 competitive equilibrium $\left(c_{0}^{0}, f_{0}^{0}, p_{0}^{0}\right)$ will also be implemented over times $t \geqq 0$, and the economy will exhibit consistency. The only way that inconsistency can arise in the present framework is for the government to veer from its optimal time- 0 policy path $g_{0}^{\circ}$. 
First, solve (1) for $c_{0}^{0}$ as a function of $\left(f_{0}^{0}, g_{0}^{0}, p_{0}^{0}, x^{0}\right)$ to obtain the time- 0 consumer choice function, denoted by

$$
\boldsymbol{c}_{0}^{0}=h_{0}^{c}\left(f_{0}^{0}, g_{0}^{0}, p_{0}^{0}, x^{0}\right) .
$$

Second, solve (2) for $\boldsymbol{f}_{0}^{0}$ as a function of $\left(\boldsymbol{c}_{0}^{0}, \boldsymbol{g}_{0}^{0}, \boldsymbol{p}_{0}^{0}, x^{0}\right)$ to obtain the time- 0 firm choice function, denoted by

$$
\boldsymbol{f}_{0}^{0}=h_{0}^{f}\left(\boldsymbol{c}_{0}^{0}, \boldsymbol{g}_{0}^{0}, \boldsymbol{p}_{0}^{0}, x^{0}\right) .
$$

Third, jointly solve (5), (6), and the market equilibrium conditions (3) to obtain the time- 0 competitive equilibrium values for $\left(\boldsymbol{c}_{0}^{0}, \boldsymbol{f}_{0}^{0}, \boldsymbol{p}_{0}^{0}\right)$ as functions of $\left(g_{0}^{0}, x^{0}\right)$, denoted by

$$
\begin{aligned}
& c_{0}^{0}=\mathrm{h}_{0}^{c^{*}}\left(g_{0}^{0}, x^{0}\right) \\
& \boldsymbol{f}_{0}^{0}=h_{0}^{f^{*}}\left(g_{0}^{0}, x^{0}\right) \\
& \boldsymbol{p}_{0}^{0}=h_{0}^{p^{*}}\left(g_{0}^{0}, x^{0}\right)
\end{aligned}
$$

Fourth, substitute (7) into the government's problem (4), thus eliminating the variables $\boldsymbol{c}_{0}^{0}, \boldsymbol{f}_{0}^{0}, \boldsymbol{p}_{0}^{0}$, and solve for $\boldsymbol{g}_{0}^{0}$ as a function solely of the current time 0 and state vector $x^{0}$ to obtain the optimal time- 0 policy path for government, denoted by

$$
\boldsymbol{g}_{0}^{0^{*}}=\left\{g^{0}\left(t, x^{0}\right) \mid t \geqq 0\right\} .
$$

Finally, substitute (8a) into (7) to obtain $\left(c_{0}^{0}, f_{0}^{0}, p_{0}^{0}\right)$ as functions solely of the current time 0 and state vector $x^{0}$, the optimal time- 0 choice paths for consumer, firm, and price, denoted by

$$
\begin{aligned}
& c_{0}^{0^{*}}=\left\{c^{0}\left(t, x^{0}\right) \mid t \geqq 0\right\} ; \\
& f_{0}^{0^{*}}=\left\{f^{0}\left(t, x^{0}\right) \mid t \geqq 0\right\} ; \\
& p_{0}^{0^{*}}=\left\{p^{0}\left(t, x^{0}\right) \mid t \geqq 0\right\} .
\end{aligned}
$$

The optimal time- 0 competitive equilibrium path $\left(c_{0}^{0^{*}}, f_{0}^{0^{*}}, g_{0}^{0^{*}}, p_{0}^{0^{*}}\right)$ will henceforth be denoted by $e_{0}^{0 *}$.

Model (1) through (4) is essentially static in that it generates the optimal path $e_{0}^{0^{*}}$ at the single point in time $\tau=0$. The verification of consistency for this economy requires the comparison of optimal paths calculated at successive current times $\tau \geqq 0$ as real time $\tau$ proceeds. It thus remains to 
specify how the consumer, the firm, and the government recalculate their optimal choice paths at successive current times $\tau \geqq 0$.

Suppose that $\tau>0$ is the new current time, and that values

$$
\left\{c^{*}(t), f^{*}(t), g^{*}(t), p^{*}(t) \mid 0 \leqq \imath<\tau\right\}
$$

for consumer, firm, and government choices and for prices have somehow been realized over times $0 \leqq t<\tau$. The new current state vector $x^{*}(\tau)$ is thus determined by

$$
x^{*}(\tau)=\int_{0}^{\tau} \dot{x}^{*}(t) \mathrm{d} t+x^{0},
$$

where the vectors $\dot{x}^{*}(t)$ are recursively generated from the state cquations

$$
\begin{aligned}
& \dot{x}^{*}(t)=S_{t}\left(c^{*}(t), f^{*}(t), g^{*}(t), p^{*}(t), x^{*}(t)\right), \quad 0 \leqq t<\tau ; \\
& x^{*}(0)=x^{0} .
\end{aligned}
$$

The optimization problem for the consumer at the new current time $\tau$ takes the form

$$
\max _{c_{\tau}^{\tau}} \int_{\tau}^{\infty} u_{t}\left(c^{\tau}(t) \mid f^{\tau}(t), g^{\tau}(t), p^{\tau}(t), x^{\tau}(t)\right) \mathrm{d} t
$$

subject to

$$
\begin{aligned}
& c^{\tau}(t) \in \mathscr{F}_{t}^{c}\left(f^{\tau}(t), g^{\tau}(t), p^{\tau}(t), x^{\tau}(t)\right), \quad t \geqq \tau ; \\
& \dot{x}^{\tau}(t)=S_{t}\left(c^{\tau}(t), f^{\tau}(t), g^{\tau}(t), p^{\tau}(t), x^{\tau}(t)\right), \quad t \geqq \tau ; \\
& x^{\tau}(\tau)=x^{*}(\tau),
\end{aligned}
$$

where the time- $\tau$ consumer choice path is denoted by $c_{\tau}^{\tau}=\left(c^{\tau}(t)\right)_{t \geq r}$. Comparing the time- $\tau$ consumer optimization problem (12) to the time-0 consumer optimization problem (1), the only changes are that the current time has been updated from 0 to $\tau$ and the current state vector has been updated from $x^{0}$ to $x^{*}(\tau)$. Let the solution to (12), the time- $\tau$ consumer choice function, be denoted by

$$
\boldsymbol{c}_{\mathrm{r}}^{\tau}=h_{\tau}^{\mathcal{c}}\left(\boldsymbol{f}_{\mathrm{r}}^{\tau}, \boldsymbol{g}_{\mathrm{r}}^{\tau}, \boldsymbol{p}_{\mathrm{r}}^{\tau}, x^{*}(\tau)\right),
$$

where

$$
\boldsymbol{f}_{\tau}^{\tau}=\left(f^{\tau}(t)\right)_{\tau \geqq \tau}, \quad \boldsymbol{g}_{\tau}^{\tau}=\left(g^{\tau}(t)\right)_{t \geqq \tau} \quad \text { and } \quad p_{\tau}^{\tau}=\left(p^{\tau}(t)\right)_{t \geqq \tau} .
$$


Similarly, the updated optimization problem (2) for the firm at the new current time $\tau$ takes the form

$$
\max _{f_{\tau}^{\tau}} \int_{\tau}^{\infty} \Pi_{t}\left(f^{\tau}(t) \mid c^{\tau}(t), g^{\tau}(t), p^{\tau}(t), x^{\tau}(t)\right) \mathrm{d} t
$$

subject to

$$
\begin{array}{ll}
f^{\tau}(t) \in \mathscr{F}_{i} f\left(c^{\tau}(t), g^{\tau}(t), p^{\tau}(t), x^{\tau}(t)\right), & t \geqq \tau ; \\
\dot{x}^{\tau}(t) & =S_{t}\left(c^{\tau}(t), f^{\tau}(t), g^{\tau}(t), p^{\tau}(t), x^{\tau}(t)\right), \quad t \geqq \tau ; \\
x^{\tau}(\tau) & =x^{*}(\tau) .
\end{array}
$$

Let the solution to (14), the time- $\tau$ firm choice function, be denoted by

$$
\boldsymbol{f}_{\tau}^{\tau}=h_{\tau}^{f}\left(\boldsymbol{c}_{\tau}^{\tau}, \boldsymbol{g}_{\tau}^{\tau}, \boldsymbol{p}_{\tau}^{\tau}, x^{*}(\tau)\right)
$$

Finally, the updated optimization problem (4) for the government at the new current time $\tau$ takes the form

$$
\max _{g_{\tau}^{\tau}} \int_{\tau}^{\infty} u_{t}\left(c^{\tau}(t) \mid f^{\tau}(t), g^{\tau}(t), p^{\tau}(t), x^{\tau}(t)\right) \mathrm{d} t
$$

subject to

$$
\begin{aligned}
& g^{\tau}(t) \in \mathscr{F}_{t}^{g}\left(c^{\tau}(t), f^{\tau}(t), p^{\tau}(t), x^{\tau}(t)\right), \quad t \geqq \tau ; \\
& \dot{x}^{\tau}(t)=S_{t}\left(c^{\tau}(t), f^{\tau}(t), g^{\tau}(t), p^{\tau}(t), x^{\tau}(t)\right), \quad t \geqq \tau ; \\
& x^{\tau}(\tau)=x^{*}(\tau) ; \\
& \boldsymbol{c}_{\tau}^{\tau}=h_{\tau}^{\tau}\left(f_{\tau}^{\tau}, g_{\tau}^{\tau}, p_{\tau}^{\tau}, x^{*}(\tau)\right) ; \\
& f_{\tau}^{\tau}=h_{\tau}^{f}\left(c_{\tau}^{\tau}, g_{\tau}^{\tau}, p_{\tau}^{\tau}, x^{*}(\tau)\right) ; \\
& 0=\mathscr{M}_{\tau}\left(c^{\tau}(t), f^{\tau}(t), g^{\tau}(t), p^{\tau}(t), \dot{p}_{+}^{\tau}(t), x^{\tau}(t)\right), \quad t \geqq \tau .
\end{aligned}
$$

In principle, the time- $\tau$ optimization problems (12), (14), and (16) can be jointly solved to obtain competitive equilibrium choice and price paths $\boldsymbol{c}_{\tau}^{\tau}, \boldsymbol{f}_{\tau}^{\tau}$, $\boldsymbol{g}_{\tau}^{\tau}, \boldsymbol{p}_{\tau}^{\tau}$ as functions solely of the new current time $\tau$ and state vector $x^{*}(\tau)$ in the same iterative manner previously described for the joint solution of (1) through (4) at time 0 with state vector $x^{0}$. Let this optimal time- $\tau$ competitive 
equilibrium path be denoted by

$$
\boldsymbol{e}_{\tau}^{\tau^{*}}=\left(\boldsymbol{c}_{\tau}^{\tau^{*}}, \boldsymbol{f}_{\tau}^{\tau^{*}}, \boldsymbol{g}_{\tau}^{\tau^{*}}, \boldsymbol{p}_{\tau}^{\tau^{*}}\right)
$$

where

$$
\begin{aligned}
& \boldsymbol{c}_{\tau}^{\tau^{*}}=\left\{c^{\tau}\left(t, x^{*}(\tau)\right) \mid t \geqq \tau\right\} \\
& \boldsymbol{f}_{\tau}^{\tau^{*}}=\left\{f^{\tau}\left(t, x^{*}(\tau)\right) \mid t \geqq \tau\right\} \\
& \boldsymbol{g}_{\tau}^{\tau^{*}}=\left\{g^{\tau}\left(t, x^{*}(\tau)\right) \mid t \geqq \tau\right\} \\
& \boldsymbol{p}_{\tau}^{\tau^{*}}=\left\{p^{\tau}\left(t, x^{*}(\tau)\right) \mid t \geqq \tau\right\}
\end{aligned}
$$

It remains to explain where the realized values (9) comes from. At each successive current time $\tau \geqq 0$ it is assumed that the time- $\tau$ components,

$$
c^{\tau}\left(\tau, x^{*}(\tau)\right), \quad f^{\tau}\left(\tau, x^{*}(\tau)\right), \quad g^{\tau}\left(\tau, x^{*}(\tau)\right), \quad p^{\tau}\left(\tau, x^{*}(\tau)\right)
$$

of the optimal time- $\tau$ path $\boldsymbol{e}_{\tau}^{\tau^{*}}$ are actually realized. A new optimal end-path is then generated based on the new current time and the new current state vector resulting from these realized values, in the manner described above. This type of updating has been referred to in the control literature as openloop feedback control' [see Saridis (1977)].

\section{Necessary and sufficient conditions for consistency}

An economy from the general class of dynamic Walrasian economies described in section 2 will be said to exhibit consistency if and only if, for every $\tau>0$, the optimal competitive equilibrium path $e_{\tau}^{\tau^{*}}$ starting at time $\tau$ with current state vector $x^{*}(\tau)$ coincides with the $[\tau, \infty)$ continuation $\boldsymbol{e}_{\tau}^{0^{*}}$ of the optimal competitive equilibrium path $\boldsymbol{e}_{0}^{0^{*}}$ starting at time 0 with state vector $x^{0}$. Thus, consistency holds if and only if, for every $\tau>0$, and for all $t \geq \tau,{ }^{7}$

$$
\left[\begin{array}{l}
c^{\tau}\left(t, x^{*}(\tau)\right) \\
f^{\tau}\left(t, x^{*}(\tau)\right) \\
g^{\tau}\left(t, x^{*}(\tau)\right) \\
p^{\tau}\left(t, x^{*}(\tau)\right)
\end{array}\right]=\left[\begin{array}{l}
c^{0}\left(t, x^{0}\right) \\
f^{0}\left(t, x^{0}\right) \\
g^{0}\left(l, x^{0}\right) \\
p^{0}\left(t, x^{0}\right)
\end{array}\right] .
$$

${ }^{7}$ The four papers initially cited in the introduction focus on the wcaker requircment of dynamic policy consistency, $g^{\tau}\left(t, x^{*}(\tau)\right)=g^{0}\left(t, x^{0}\right), t \geqq \tau>0$, and derive examples of economies where it fails to hold. As illustrated by these examples, consistency normally prevails for one of the components in (19) if and only if it prevails for all of them. Thus, to avoid discussion of degenerate special cases, attention is focused in the present paper on the stronger consistency requirement (19). 
The present section establishes general necessary and sufficient conditions for consistency. ${ }^{8}$ Proofs are given in the appendix.

The derivation of necessary and sufficient conditions for consistency proceeds by comparing the structure of the time- 0 government optimization problem (4) to the structure of the time- $\tau$ government optimization problem (16) for any arbitrary time $\tau>0$. Certain preliminaries are needed for this comparison.

First, the following notational conventions will be used. Define the virtual time- 0 state path $x_{0}^{0}$ to be the path of state vectors $x^{0}(t), t \geqq 0$, that would prevail if the optimal time-0 path $e_{0}^{0^{*}}$ were actually carried out. Thus, $x_{0}^{0}$ is the solution to the state equations

$$
\begin{aligned}
& \dot{x}^{0}(t)=S_{t}\left(c^{0}\left(t, x^{0}\right), f^{0}\left(t, x^{0}\right), g^{0}\left(t, x^{0}\right), p^{0}\left(t, x^{0}\right), x^{0}(t)\right), \quad \imath \geqq 0 ; \\
& x^{0}(0)=x^{0} .
\end{aligned}
$$

Also, for each $s$ and $\tau$ satisfying $0 \leqq s<\tau$, let the $[s, \tau)$ segments of the optimal time- 0 path $\boldsymbol{e}_{0}^{0^{*}}$ be abbreviated by

$$
\begin{aligned}
& \boldsymbol{c}_{s, \tau}^{0^{*}}=\left(c^{0}\left(t, x^{0}\right)\right)_{s \leqq t<\tau} ; \\
& \boldsymbol{f}_{s, \tau}^{0^{*}}=\left(f^{0}\left(t, x^{0}\right)\right)_{s \leqq t<\tau} ; \\
& \boldsymbol{g}_{s, \tau}^{0^{*}}=\left(g^{0}\left(t, x^{0}\right)\right)_{s \leqq t<\tau} ; \\
& \boldsymbol{p}_{s, \tau}^{0^{*}}=\left(p^{0}\left(t, x^{0}\right)\right)_{s \leqq t<\tau} .
\end{aligned}
$$

Thus, for example, $c_{0}^{0^{*}}=\left(c_{0, \tau}^{0^{*}}, c_{\tau}^{0^{*}}\right)$.

Second, a simple examination of the nested structure of the time- 0 consumer optimization problem (1) reveals that its solution, the time-0 consumer choice function $h_{0}^{c}$ depicted in (5), is weakly time separable in the following sense: ${ }^{9}$ for every $t \geqq 0$, the time- $t$ component function of $h_{0}^{c}$, denoted by $H_{t}^{c}$, depends at most on time-s variables for current and future times $s \geqq t$. Formally,

$$
\boldsymbol{c}_{0}^{0}=h_{0}^{c}\left(\boldsymbol{f}_{0}^{0}, \boldsymbol{g}_{0}^{\mathbf{0}}, \boldsymbol{p}_{0}^{\mathbf{0}}, x^{0}\right)=\left(H_{t}^{c}\left(\boldsymbol{f}_{t}^{0}, \boldsymbol{g}_{t}^{0}, \boldsymbol{p}_{t}^{0}, x^{0}(t)\right)\right)_{t \geqq 0},
$$

\footnotetext{
${ }^{8}$ These necessary and sufficient conditions are derived under the following maintained existence and uniqueness assumptions: (1) The time- $\tau$ consumer and firm choice functions (13) and (15) exist and are unique for every current time $\tau \geqq 0$; (2) the state equations (12c) have a unique solution $\boldsymbol{x}_{\tau}$ for any feasible set of conditioning variables $\left\{\boldsymbol{c}_{\tau}, \boldsymbol{f}_{\tau}, \boldsymbol{g}_{\tau}, \boldsymbol{p}_{\mathrm{r}}, x(\tau)\right\}, \tau \geq 0$; and (3) the optimal time- $\tau$ path (17) exists and is unique for every current time $\tau \geqq 0$.

${ }^{9}$ Continuity requirements for the consumer and firm choice paths $c_{0}^{0}$ and $f_{0}^{0}$ would destroy even weak time separability. In the present paper no such global restrictions are imposed on the solutions $\boldsymbol{c}_{\mathfrak{\tau}}^{\tau}$ and $\boldsymbol{f}_{\mathfrak{t}}^{\tau}$ to the consumer and firm time- $\tau$ optimization problems (12) and (14), $\tau \geqq 0$.
} 
where

$$
\begin{aligned}
& c^{0}(t)=H_{t}^{c}\left(f_{t}^{0}, g_{t}^{0}, p_{t}^{0}, x^{0}(t)\right), \quad t \geqq 0 ; \\
& f_{t}^{0}=\left(f^{0}(s)\right)_{s \geqq t}, \quad g_{t}^{0}=\left(g^{0}(s)\right)_{s \geqq t}, \quad p_{t}^{0}=\left(p^{0}(s)\right)_{s \geqq t},
\end{aligned}
$$

and the state vectors $x^{0}(t)$ satisfy the state equations (20). Similarly, the time-0 firm choice function $h_{0}^{f}$ depicted in (6), the solution function for the time-0 firm optimization problem (2), is weakly time separable. Specifically, letting the component functions of $h_{0}^{f}$ be denoted by $H_{t}^{f}, t \geqq 0$,

$$
f_{0}^{0}=h_{0}^{f}\left(c_{0}^{0}, g_{0}^{0}, p_{0}^{0}, x^{0}\right)=\left(H_{t}^{f}\left(c_{t}^{0}, g_{t}^{0}, p_{t}^{0}, x^{0}(t)\right)\right)_{t \geqq 0},
$$

where

$$
\begin{aligned}
& f^{0}(t)=H_{t}^{f}\left(c_{t}^{0}, g_{t}^{0}, p_{t}^{0}, x^{0}(t)\right), \quad t \geqq 0 ; \\
& c_{t}^{0}=\left(c^{0}(s)\right)_{s \geqq t},
\end{aligned}
$$

and the statc vectors $x^{0}(t)$ satisfy the state cquations (20).

Now consider the time- 0 government optimization problem (4). Let $\tau>0$ be an arbitrary future time. The optimal time- 0 paths (8) which solve problem (4) are unchanged if the time- 0 paths $c_{0}^{0}, f_{0}^{0}, g_{0}^{0}, \boldsymbol{p}_{0}^{0}$ appearing in problem (4) are preset to their optimal time- 0 values over the initial time segment $[0, \tau)$. Thus, using the previously introduced notation $(20)$ through (23), the time- 0 government optimization problem (4) is equivalent to the following optimization problem in the sense that the same optimal time- 0 path $e_{0}^{0^{*}}$ is generated from its solution:

$$
\max _{g_{\tau}^{0}} \int_{\tau}^{\infty} u_{t}\left(c^{0}(t) \mid f^{0}(t), g^{0}(t), p^{0}(t), x^{0}(t)\right) \mathrm{d} t
$$

subject to

$$
\begin{aligned}
& g^{0}(t) \in \mathscr{F}_{t}^{g}\left(c^{0}(t), f^{0}(t), p^{0}(t), x^{0}(t)\right), \quad t \geqq \tau ; \\
& \dot{x}^{0}(t)=S_{t}\left(c^{0}(t), f^{0}(t), g^{0}(t), p^{0}(t), x^{0}(t)\right), \quad t \geqq \tau ; \\
& c_{\tau}^{0}=h_{\tau}^{c}\left(f_{\tau}^{0}, g_{\tau}^{0}, p_{\tau}^{0}, x^{0}(\tau)\right) ; \\
& f_{\tau}^{0}=h_{\tau}^{f}\left(c_{\tau}^{0}, g_{\tau}^{0}, p_{\tau}^{0}, x^{0}(\tau)\right) ; \\
& 0=\mathscr{M}_{\tau}\left(c^{0}(t), f^{0}(t), g^{0}(t), p^{0}(t), \dot{p}_{+}^{0}(t), x^{0}(t)\right), \quad t \geqq \tau ; \\
& c_{0, \tau}^{0}=c_{0, \tau}^{0^{*}} ; \quad f_{0, \tau}^{0}=f_{0, \tau}^{0^{*}} ; \quad g_{0, \tau}^{0}=g_{0, \tau}^{0^{*}} ; \quad p_{0, \tau}^{0}=p_{0, \tau}^{0^{*}} ;
\end{aligned}
$$




$$
\begin{aligned}
& c^{0}\left(s, x^{0}\right)=H_{s}^{c}\left(f_{s, \tau}^{0^{*}}, \boldsymbol{f}_{\tau}^{0}, \boldsymbol{g}_{s, \tau}^{0^{*}}, \boldsymbol{g}_{\tau}^{0}, \boldsymbol{p}_{s, \tau}^{0^{*}}, \boldsymbol{p}_{\tau}^{0}, x^{0}(s)\right), \quad 0 \leqq s<\tau ; \\
& f^{0}\left(s, x^{0}\right)=H_{s}^{f}\left(\boldsymbol{c}_{s, \tau}^{0^{*}}, \boldsymbol{c}_{\tau}^{0}, \boldsymbol{g}_{s, \tau}^{0^{*}}, \boldsymbol{g}_{\tau}^{0}, \boldsymbol{p}_{s, \tau}^{0^{*}}, \boldsymbol{p}_{\tau}^{0}, x^{0}(s)\right), \quad 0 \leqq s<\tau .
\end{aligned}
$$

The optimization problem (24) is simply the time-0 government optimization problem (4) with the $[0, \tau)$ initial segments $c_{0, \tau}^{0}, f_{0, \tau}^{0}, g_{0, \tau}^{0}, p_{0, \tau}^{0}$ of the time-0 paths $c_{0}^{0}, f_{0}^{0}, g_{0}^{0}, p_{0}^{0}$ preset to their optimal time- 0 values via constraint $(24 \mathrm{~g})$. Note that the state vectors which appear in (24) are the virtual state vectors generated by (20). The final constraints $(24 \mathrm{~h})$ and (24i) are the constraints placed on the choice and price variables $\left(\boldsymbol{c}_{\tau}^{0}, \boldsymbol{f}_{\tau}^{0}, \boldsymbol{g}_{\tau}^{0}, \boldsymbol{p}_{\tau}^{0}\right)$ for times $t \geqq \tau$ by the requirement that the consumer and firm choice vectors for time 0 up to time $\tau$ be optimally chosen from the vantage point of the consumer and firm at time 0 .

Suppose that the economy consistently implements the optimal time-0 path $e_{0}^{0^{*}}$ over the time interval $[0, \tau)$, so that the new current time is $\tau$ and the new current state is $x^{*}(\tau)=x^{0}(\tau)$. The government now faces the time- $\tau$ optimization problem $(16)$ with $x^{*}(\tau)=x^{0}(\tau)$. This problem has exactly the same structure as the first six components (24a)-(24) of problem (24); that is, problem (16) with $x^{*}(\tau)=x^{0}(\tau)$ is nested within problem (24).

Consider the final two constraints $(24 \mathrm{~h})$ and (24i) in problem (24) which do not appear in problem (16) with $x^{*}(\tau)=x^{0}(\tau)$. As of time $\tau$, the left-hand-side variables and the starred right-hand-side variables of $(24 \mathrm{~h})$ and (24i) have actually been implemented; the future time $t \geqq \tau$ variables $\left(\boldsymbol{c}_{\tau}^{0}, \boldsymbol{f}_{\tau}^{0}, \boldsymbol{g}_{\tau}^{0}, \boldsymbol{p}_{\tau}^{0}\right)$ have not yet been realized. Thus, as of time $\tau$, constraints $(24 \mathrm{~h})$ and $(24 \mathrm{i})$ can be restated as general constraints on the yet-to-be-realized variables $\left(\boldsymbol{c}_{\tau}, \boldsymbol{f}_{\tau}, \boldsymbol{g}_{\tau}, \boldsymbol{p}_{\tau}\right)$, of the form

$$
\begin{array}{ll}
c^{0}\left(s, x^{0}\right)=H_{s}^{c}\left(f_{s, \tau}^{0^{*}}, \boldsymbol{f}_{\tau}, \boldsymbol{g}_{s, \tau}^{0^{*}}, \boldsymbol{g}_{\tau}, \boldsymbol{p}_{s, \tau}^{0^{*}}, \boldsymbol{p}_{\tau}, x^{0}(s)\right), & 0 \leqq s<\tau \\
f^{0}\left(s, x^{0}\right)=H_{s}^{f}\left(\boldsymbol{c}_{s, \tau}^{0^{*}}, \boldsymbol{c}_{\tau}, \boldsymbol{g}_{s_{, \tau}}^{0^{*}}, \boldsymbol{g}_{\tau}, \boldsymbol{p}_{\mathrm{s}, \tau}^{0^{*}}, \boldsymbol{p}_{\tau}, x^{0}(s)\right), & 0 \leqq s<\tau
\end{array}
$$

By definition (19), consistency continues to hold at time $\tau$ if and only if the solution $\boldsymbol{e}_{\tau}^{\tau^{*}}=\left(\boldsymbol{c}_{\tau}^{\tau^{*}}, \boldsymbol{f}_{\tau}^{\tau^{*}}, \boldsymbol{g}_{\tau}^{\boldsymbol{\tau}^{*}}, \boldsymbol{p}_{\tau}^{\tau^{*}}\right)$ to the time- $\tau$ optimization problem (16) with $x^{*}(\tau)=x^{0}(\tau)$ coincides with the $[\tau, \infty)$ continuation $\boldsymbol{e}_{\tau}^{0^{*}}=\left(c_{\tau}^{0^{*}}, \boldsymbol{f}_{\tau}^{0^{*}}, \boldsymbol{g}_{\tau}^{0^{*}}, \boldsymbol{p}_{\tau}^{0^{*}}\right)$ of the optimal time- 0 path $e_{0}^{0^{*}}$. By construction, the particular values assigned to $\left(\boldsymbol{c}_{\tau}, \boldsymbol{f}_{\tau}, \boldsymbol{g}_{\tau}, \boldsymbol{p}_{\tau}\right)$ by $\boldsymbol{e}_{\tau}^{0^{*}}$ satisfy the constraints $(25)$; thus the particular values assigned to $\left(c_{\tau}, f_{\tau}, g_{\tau}, p_{\tau}\right)$ by $e_{\tau}^{\tau^{*}}$ must also satisfy the constraints (25) in order for consistency to hold at $\tau$. In particular, then, the choices made by the consumer, firm, and government at time 0 for implementation over the time interval $[0, \tau)$ must not be regretted at time $\tau$. Constraints (25) are thus appropriately referred to as time- $\tau$ ex post optimality constraints.

The difficulty is that the time- $\tau$ ex post optimality constraints (25) do not 
explicitly appear in the constraint set for problem (16). Thus, unless these constraints are either trivial or redundant for problem (16), the solution $\boldsymbol{e}_{\tau}^{\tau^{* *}}$ to problem (16) will not satisfy them, and inconsistency will prevail.

The satisfaction of the time- $\tau$ ex post optimality constraints (25) by $e_{\tau}^{\tau^{*}}$ for every $\tau>0$ is thus a necessary condition for consistency. Conversely, as the following theorem shows, the redundancy of constraints (24h) and (24i) for problem (24) for every $\tau>0$ is a sufficient condition for consistency. A discussion of this sufficient condition for consistency is provided in section 4 , below.

Theorem 3.1. (Basic consistency theorem). A necessary condition for consistency is that the time- $\tau$ ex post optimality constraints (25) are redundant for problem (16) for every $\tau>0$, in the sense that they can be appended to the constraints of (16) as restrictions on $\left(\boldsymbol{c}_{\mathfrak{\tau}}^{\tau}, \boldsymbol{f}_{\mathfrak{\tau}}^{\tau}, \boldsymbol{g}_{\tau}^{\tau}, \boldsymbol{p}_{\tau}^{\tau}\right)$ without affecting the solution $\boldsymbol{e}_{\tau}^{r^{*}}$ of (16). A sufficient condition for consistency is that the time-0 constraints (24h) and (24i) are redundant for problem (24) for every $\tau>0$, in the sense that they can be deleted from the constraints of (24) without affecting the solution $e_{0}^{0^{*}}$ of $(24)$.

\section{The sufficient condition for consistency: Special cases}

The sufficient condition for consistency in Theorem 3.1 holds in two special cases: either (a) the consumer and firm exhibit perfect myopic foresight at time 0 , in the sense [Burmeister (1980)] that the consumer and firm choice vectors $c^{0}(t)$ and $f^{0}(t)$ depend at most on the levels and right derivatives of timc- $t$ variables, $t \geqq 0$; or (b) the consumcr has essentially complete structural information at time 0 , in the sense that the consumer's feasible choice sets for current and future times incorporate any constraint faced by government which is affected by the consumer's choice vectors.

The first special case (a) implies that the constraints (24h) and (24i) are trivially redundant for problem (24), since they impose no restriction on the future variables $\left[\boldsymbol{c}_{\tau}^{0}, \boldsymbol{f}_{\tau}^{0}, \boldsymbol{g}_{\tau}^{0}, \boldsymbol{p}_{\tau}^{0}\right]$. Formally, the following corollary holds:

Corollary 4.1. (Consistency with perfect myopic foresight). A sufficient condition for consistency is that the time-0 consumer and firm choice functions $h_{0}^{c}$ and $h_{0}^{f}$ exhibit perfect myopic foresight, in the sense that their component functions $H_{t}^{c}$ and $H_{t}^{f}$ have the general structural form

$$
\begin{aligned}
& c^{0}(t)=H_{+}^{c}\left(f^{0}(t), \dot{f}_{+}^{0}(t), g^{0}(t), \dot{g}_{+}^{0}(t), p^{0}(t), \dot{p}_{+}^{0}(t), x^{0}(t)\right), \quad t \geqq 0 ; \\
& f^{0}(t)=H_{i}^{f}\left(c^{0}(t), \dot{c}_{+}^{0}(t), g^{0}(t), \dot{g}_{+}^{0}(t), p^{0}(t), \dot{p}_{+}^{0}(t), x^{0}(t)\right), \quad t \geqq 0 .
\end{aligned}
$$

Perfect myopic foresight, as embodied in Corollary 4.1, requires that 
future (time $s>t$ ) variables not appear as conditioning variables for the time-t choice vectors selected by the consumer and firm at time 0 . Various wellknown macrodynamic studies [e.g. Lucas (1975, 1978)] directly postulate demand and supply functions for private agents which satisfy this requirement. For example, Lucas (1978) assumes that private agents condition their time- $t$ choices only on the time- $t$ state vector (output and share levels) and the time- $t$ equilibrium price expressed as a function of the time- $t$ state vector. He thus obtains standard feedback control law representations,

$$
\begin{aligned}
& c^{0}(t)=H_{t}^{c}\left(x^{0}(t)\right), \quad t \geqq 0 ; \\
& f^{0}(t)=H_{t}^{f}\left(x^{0}(t)\right), \quad t \geqq 0,
\end{aligned}
$$

for his agent's time-0 choice functions, a special case of (26).

In the present context, restrictions on criterion functions and feasible choice sets which guarantee that the time- 0 choice functions for both the consumer and the firm have the perfect myopic representations (26) are extremely stringent. ${ }^{10}$ The consumer and firm optimization problems (1) and (2) must each be equivalently expressible as a sequence of myopic period-byperiod optimization problems. Roughly, this requires maximum future expected returns to be positively correlated with current returns for every successive current time $\tau$ [see Tesfatsion (1980)].

The second special case (b) for which consistency holds, i.e essentially complete structural information on the part of the consumer at time 0 , implies that the constraints $(24 \mathrm{~h})$ and (24i) are redundant for problem (24) even if they impose nontrivial restrictions on future variables. Special case (b) requires that the consumer's time- 0 feasible choice sets incorporate every constraint facing the government at time 0 which is in any way affected by the consumer's time- 0 choice path $c_{0}^{0}$. As shown in the appendix proof of the following corollary, no discrepancy then arises between what the government perceives to be optimal for the consumer and what the consumer perceives to be optimal for himself. The consumer and the government face exactly the same optimization problem at time 0 , except for the variables they control. As noted by Fischer (1980, p. 106), this is sufficient for consistency. ${ }^{11}$

\footnotetext{
${ }^{10}$ Perfect myopic foresight holds for the time- 0 firm choice function in each of the inconsistency examples presented in the four papers initially cited in the introduction. Either the firm is absent [Fischer (1980)], or the firm is directly modelled as a myopic period-by-period profit maximizer with no capital holdings [Calvo (1978), Kydland and Prescott (1980), Turnovsky and Brock (1980)]. However, perfect myopic foresight fails to hold for the time-0 consumer choice function [see Tesfatsion (1984a, appendix II.3)].

${ }^{11}$ In particular, under special case (b) the consumer and the government incorporate all relevant aspects of the firm into their optimization problems in exactly the same way. Whether or not the firm has correct and essentially complete structural information is then irrelevant from the standpoint of consistency.
} 
Corollary 4.2. (Consistency with essentially complete structural information). Consistency prevails if the consumer has essentially complete structural information at time 0 , here defined to mean that each of the following three conditions is satisfied:

(i) Either the government feasible choice sets are independent of the consumer's choice path $c_{0}^{0}$, or the consumer's feasible choice sets incorporate the government's feasible choice sets in the sense that

$$
c^{0}(t) \in \mathscr{F}_{t}^{c}\left(f^{0}(t), g^{0}(t), p^{0}(t), x^{0}(t)\right), \quad t \geqq 0,
$$

implies

$$
g^{0}(t) \in \mathscr{F}_{t}^{g}\left(c^{0}(t), f^{0}(t), p^{0}(t), x^{0}(t)\right), \quad t \geqq 0 .
$$

(ii) Either the time-0 market equilibrium conditions (3) are independent of the consumer's time-0 choice path $c_{0}^{0}$, or the consumer's feasible choice sets incorporate these market equilibrium conditions in the sense that (28) implies

$$
0=\mathscr{M}_{\mathrm{r}}\left(c^{\mathrm{o}}(t), f^{0}(t), g^{0}(t), p^{0}(t), \dot{p}_{+}^{0}(t), x^{0}(t)\right), \quad t \geqq 0 .
$$

(iii) Either the firm's time-0 choice function exhibits perfect myopic foresight in the sense of (26b), and is independent of the consumer's time-0 choice path $c_{0}^{0}$, or the consumer's feasible choice sets incorporate the firm's time-0 choice function in the sense that (28) implies

$$
f^{0}(t)=H_{t}^{f}\left(c_{t}^{0}, g_{t}^{0}, p_{t}^{0}, x^{0}(t)\right), \quad t \geqq 0 .{ }^{12}
$$

Essentially complete structural information, as defined by conditions (i), (ii), and (iii) in Corollary 4.2, requires the consumer to act as if he understands how his choices impact on prices and government policy variables through the constraints faced by government. This requirement is satisfied if the firm is simply an extension of the consumer sector with entirely harmonious objectives and consumer choice variables do not appear in the government's feasible choice sets. The latter condition is met, for example, if government at each time $t$ relies solely on lump-sum taxes and/or taxes imposed on assets incorporated into the time- $t$ state vector. [See the discussion of the Fischer (1980) model in section 6, below.]

However, aside from this important but rather stringent set of circumstances, essentially complete structural information violates the usual Walrasian assumptions concerning information decentralization. Moreover, it is unclear

\footnotetext{
${ }^{12}$ If (28) implies (31), then the firm's time-0 choice function must have an equivalent perfect myopic foresight representation; for the consumer's feasible choice sets in (28) are strongly time separable.
} 
whether a direct generalization of conditions (i), (ii), and (iii) to multiconsumer economies would still be sufficient for consistency. Suppose the decisions of the consumers have a significant aggregate impact on the constraints faced by government, but are each individually insignificant. Then, even if the consumers have complete information regarding the constraints faced by government, it may not be individually rational for them to take these constraints into account.

\section{Relation to the two basic welfare theorems}

Given well-known regularity conditions, the two basic theorems of welfare economics for standard Walrasian economies assert that every competitive equilibrium allocation is Pareto optimal and that every Pareto optimal allocation can be price-supported as a competitive equilibrium, given an appropriate redistribution of initial resources and profit shares [see Nikaido (1968, section 17)]. Consumers in standard Walrasian economies obtain no direct utility from government activities. However, analog welfare theorems have been obtained for Walrasian economies with public sectors in which government goods and services enter directly into agents' utility functions [see Milleron (1972, pp. 434-435)].

For the class of dynamic Walrasian cconomies treatcd in the present paper, with a benevolent government attempting to maximize the lifetime utility of a single representative consumer, the concepts of first-best optimality and Pareto optimality coincide. It is first shown below that a Pareto optimal time-0 path for such an economy can be supported as an optimal time- 0 competitive equilibrium path only if the latter path is consistent. The necessity of consistency in this case is fairly obvious, and has been noted by other authors in other contexts [Fischer (1980, p. 95) and Hillier and Malcomson (1984, p. 1441)]. More interesting is the failure of the converse statement, also established below; namely, consistent optimal time- 0 competitive equilibrium paths need not be Pareto optimal.

\subsection{Necessity of consistency for the support of Pareto optimal paths}

Consider an economy from the class of dynamic Walrasian economies described in section 2 for which the time- 0 lifetime utility function of the consumer is independent of prices and states, as in standard Walrasian economies, and depends on the government policy path $\boldsymbol{g}_{0}^{0}$ through a (possibly trivial) subsequence of policy variables $g \mathbf{l}_{0}^{0}$, where $g_{0}^{0}=\left(g 1_{0}^{0}, g 2_{0}^{0}\right)$. Let this time-0 lifetime utility function be denoted by

$$
\left.U_{0}\left(c_{0}^{0} \mid f_{0}^{0}, g I_{0}^{0}\right) \equiv \int_{0}^{\infty} u_{t}\left(c^{0}(t)\right) \mid f^{0}(t), g 1^{0}(t)\right) \mathrm{d} t .
$$


For such an economy, a time-0 (technologically) feasible path $\boldsymbol{a}_{0}^{0 \#}=$ $\left(c_{0}^{0 \#}, f_{0}^{0 \#}, g 1_{0}^{0 \#}\right)$ is Pareto optimal if there exists no other time-0 feasible path $a_{0}^{0}=\left(c_{0}^{0}, f_{0}^{0}, g I_{0}^{0}\right)$ satisfying

$$
U_{0}\left(c_{0}^{0} \mid f_{0}^{0}, g I_{0}^{\circ}\right)>U_{0}\left(c_{0}^{0 *} \mid f_{0}^{0 *}, g I_{0}^{0 *}\right) .
$$

Thus, a time- 0 feasible path is Pareto optimal if and only if it is also firstbest optimal, in the sense that it maximizes the time-0 lifetime utility of the consumer subject only to technological feasibility constraints.

Suppose a Pareto optimal time-0 path $a_{0}^{0 \#}=\left(c_{0}^{0 \#}, f_{0}^{0 \#}, g 1_{0}^{0 \#}\right)$ can be supported at time 0 as an optimal competitive equilibrium path; i.e. suppose there exists a price path $p_{0}^{0 \#}$ and a government policy path $g 2_{0}^{0 \#}$ such that

$$
e_{0}^{0 \#}=\left(c_{0}^{0 \#}, f_{0}^{0 \#}, g 1_{0}^{0 \#}, g 2_{0}^{0 \#}, p_{0}^{0 \#}\right)
$$

satisfies the time-0 government optimization problem (4). Then $e_{0}^{0 \#}$ must be consistent; for inconsistency means that government will veer away from $g_{0}^{0 \#}=\left(g 1_{0}^{0 \#}, g 2_{0}^{0 \#}\right)$ at some later time $\tau>0$ because some other feasible government policy path $\boldsymbol{g}_{\tau}^{\tau}$ results in a time- $\tau$ competitive equilibrium path $\boldsymbol{e}_{\tau}^{\tau}=\left(\boldsymbol{c}_{\tau}^{\tau_{\tau}}, \boldsymbol{f}_{\tau}^{\tau_{\tau}}, \boldsymbol{g}_{\tau}^{\tau_{\tau}}, \boldsymbol{p}_{\tau}^{\tau}\right)$ which yields greater utility $U_{\tau}\left(c_{\tau}^{\tau} \mid \boldsymbol{f}_{\tau}^{\tau}, g \boldsymbol{l}_{\tau}^{\tau}\right)$ to the consumer over times $t \geqq \tau$. It follows that

$$
a_{0}^{0^{-}} \equiv\left(c_{0, \tau}^{0 \#}, c_{\tau}^{\tau_{\tau}}, f_{0, \tau}^{0 \#}, f_{\tau}^{\tau^{*}}, g l_{0, \tau}^{0 \#}, g 1_{\tau}^{\tau}\right)
$$

is a feasible time- 0 path which yields greater time- 0 lifetime utility $U_{0}$ to the consumer than $a_{0}^{0 \#}$, a contradiction of the assumed Pareto optimality of $a_{0}^{0 \#}$.

\subsection{Consistency does not imply Pareto optimality}

Now consider the following proposition. Suppose an economy satisfying (32) exhibits consistency, i.e. suppose the $[\tau, \infty)$ continuation $\boldsymbol{e}_{t}^{0^{*}}$ of the solution $e_{0}^{0^{*}}=\left(c_{0}^{0^{*}}, f_{0}^{0^{*}}, g_{0}^{0^{*}}, p_{0}^{0^{*}}\right)$ to the time-0 government optimization problem (4) coincides with the solution $e_{\tau}^{\tau^{*}}$ to the time- $\tau$ government optimization problem (16) for every $\tau>0$. Does it necessarily follow that the time- 0 path $a_{0}^{0^{*}}=\left(c_{0}^{0^{*}}, f_{0}^{0^{*}}, g 1_{0}^{0^{*}}\right)$ is Pareto optimal?

The answer is no. As shown in Tesfatsion (1984a, appendices I.1 and II.3), Fischer's (1980) two-period economy consisting of a consumer and a benevolent government has a consistent optimal time- 0 competitive equilibrium solution in the special case when two particular exogenous parameters, $\alpha$ and $a$, are set equal to zero; for then the consumer exhibits perfect myopic foresight. The first- and second-period consumption levels $\left(c^{0^{*}}(1), c^{0^{*}}(2)\right)$ and the government spending level $g^{0^{*}}(2)$ for this consistent solution satisfy

$$
c^{0^{*}}(1)=\frac{R k_{1}}{1+\bar{\delta}}>\underset{1+\delta(1+\beta)}{-R k_{1}}=c^{0 \#}(1) ;
$$




$$
\begin{aligned}
& c^{0^{*}}(2)=\frac{\delta R c^{0^{*}}(1)}{1+\beta}<\delta R c^{0 \#}(1)=c^{0 \#}(2) ; \\
& g^{0^{*}}(2)=\beta c^{0^{*}}(2)<\beta c^{0 \#}(2)=g^{0 \#}(2),
\end{aligned}
$$

where $\left(c^{0 \#}(1), c^{0 \#}(2), g^{0 \#}(2)\right)$ denotes the unique Pareto optimal time-0 solution for Fischer's economy. The consumer achieves strictly lower utility under the consistent solution than under the Pareto optimal solution. ${ }^{13}$

The following theorem summarizes these observations on the supportability of Pareto optimal paths for the class of economies described in section 2.

Theorem 5.1. (Supportability theorem). A Pareto optimal time-0 path for an economy satisfying (32) can be supported at time 0 as an optimal competitive equilibrium path only if consistency prevails. However, there exist consistent optimal time-0 competitive equilibrium paths which are not Pareto optimal.

\section{Relation to previous studies}

In each of the inconsistency examples presented in the four papers initially cited in the introduction, the necessary condition for consistency stated in Theorem 3.1 fails to hold [see Tesfatsion (1984a, appendix)]. The results of section 3 therefore provide a systematic structural explanation for the inconsistency exhibited in these examples. All four papers recognize that the crux of the inconsistency problem in their examples is that current decisions of private agents depend on anticipated future government actions. The results of section 3 clarify the precise nature of the problem in a more general setting.

Fischer, and Turnovsky and Brock, also provide economic explanations for the inconsistency which occurs in their examples. Fischer (1980, p. 98) finds that inconsistency occurs 'only because the government has no nondistorting taxes (or their equivalent) available'. Turnovsky and Brock (1980, p. 208) find that the optimal policy is ... inconsistent in cases where only the fiscal instruments are optimized. (Consistency) will prevail if the monetary instruments are being optimized .... How do these conclusions relate to the necessary and sufficient conditions for consistency presented in sections 3 and 4 ?

\footnotetext{
${ }^{13}$ Using Bellman's Principle of Optimality (backwards optimization), Fischer (1980, sections 5 and 7) establishes the existence of a consistent path yielding lower time-0 lifetime utility $U_{0}$ than the Pareto optimal solution (command optimum) for his economy. However, Fischer's hackwards optimization procedure forces government to ignore constraints (24h) and (24i) when selecting its time-0 policy path $g_{0}^{0}$. Hence, Fischer's consistent path is not a solution for his economy in the sense of satisfying the time- 0 government optimization problem (4). In contrast, the present section establishes that consistent solutions $e_{0}^{0^{*}}$ for (4) need not be Pareto optimal.
} 
For the class of economies described in section 2, Fischer's requirement that government rely solely on nondistortionary policy instruments when selecting its time- 0 policy path $g_{0}^{0}$ translates into the requirement that the time- $t$ feasible choice set $\mathscr{F}_{t}^{g}\left(c^{0}(t), f^{0}(t), p^{0}(t), x^{0}(t)\right)$ for government's time- $t$ policy vector $g^{0}(t)$ be independent of the consumer choicc vector $c^{0}(t)$ and the firm choice vector $f^{0}(t)$ for every $t \geqq 0$. The simplest type of policy satisfying this requirement is a tax-transfer policy financed at each time $t$ by lump-sum taxes and/or taxes imposed on assets appearing in the time- $t$ state vector.

Fischer's model has no firm sector and no market clearing conditions; and, when government relies solely on nondistortionary policy instruments, no consumer choice variables appear in the government's feasible choice sets. Special case (b) (i.e. Corollary 4.2) then holds and consistency prevails. Indeed, as Fischer shows, the first-best ('command') optimum is achieved. However, as Corollary 4.2 also indicates, reliance on nondistortionary policy instruments is not always sufficient for consistency when firms and market equilibrium conditions are present.

For example, Fischer's one-good two-period model having only a consumer and a government is extended in Tesfatsion (1984b) to include a firm producing the good by means of hired labor and owned capital (good) endowment, with all profits distributed back to the consumer. The government supplies a public good in period two, financed solely by lump-sum taxes imposed on the consumer and the firm. The resulting economy exhibits inconsistency over a broad and reasonable range of parameter values, despite the fact that government relies solely on nondistortionary policy instruments.

In the Turnovsky-Brock model (1980, sections 2 and 3), the time- $t$ fiscal policy variables are given by government expenditure and an income tax rate, here denoted by

$$
(z(t), y(t))
$$

and the time-t monetary policy variables are given by changes in real money and bond supplies, here denoted by

$$
\left(\dot{m}_{+}^{s}(t), \dot{b}_{+}^{s}(t)\right)
$$

Using the detailed specification for the Turnovsky-Brock model given in Tesfatsion (1984a, appendix I.3), it can be shown that the time-0 firm choice function $h_{0}^{f}$ has the perfect myopic foresight representation $f^{0}(t)=H_{t}^{f}\left(p^{0}(t)\right)$, $t \geqq 0$. Also, as shown in Turnovsky and Brock (1980, pp. 189-190, (5) and (16)), the optimal time-0 consumer choice vectors $c^{\circ}(t)$ satisfy equations of the form

$$
c^{\circ}(t)=B^{c}\left(f^{\circ}(t), z^{o}(t), y^{\circ}(t), p^{\circ}(t), x^{\circ}(t), \mu^{\circ}(t)\right), \quad t \geqq 0 ;
$$




$$
\dot{\mu}^{0}(t)=B^{\mu}\left(y^{0}(t), p^{0}(t), \dot{p}_{+}^{0}(t), \mu^{0}(t)\right), \quad t \geqq 0,
$$

where $\mu^{0}(t)$ is a Lagrange multiplier satisfying a boundary (transversality) condition at infinity.

Turnovsky and Brock (1980, scction 4.1) first consider the case in which the fiscal policy variables (37) remain constant for all $t \geqq 0$, and government optimizes solely with respect to the monetary policy variables (38). They construct a stationary solution to the first-order necessary conditions for government's time- 0 optimization problem in which $\dot{\mu}^{0}(t)=0$ for all $t \geqq 0$ and $\mu^{0}(0)$ is determined as a function of $\left(z^{0}(0), y^{0}(0)\right)$. It follows by $(39)$ and earlier discussion that both the consumer and the firm exhibit perfect myopic foresight along this stationary solution path. Thus, special case (a) (i.e. Corollary 4.1) holds, and consistency prevails in accordance with the finding of Turnovsky and Brock (1980, p. 196).

Turnovsky and Brock (1980, sections 4.2 and 4.3) next consider what happens when government optimally chooses: (i) the monetary policy variables (38) and the income tax rate $y^{0}(t)$, keeping government expenditure $z^{0}(t)$ constant; and (ii) both the monetary policy variables (38) and the fiscal policy variables (37). In each case they are able to construct a stationary solution with $\dot{\mu}^{0}(t) \equiv 0$, and consistency prevails as before. Finally, Turnovsky and Brock (1980, section 4.4) consider what happens when government optimizes solely with respect to the income tax rates $y^{0}(t)$, or solely with respect to the government expenditure levels $z^{0}(t)$. A stationary solution no longer exists, and $\dot{\mu}^{0}(t)$ depends nontrivially on $\left(y^{0}(t), p^{0}(t), \dot{p}_{+}^{0}(t)\right)$ in $(39 \mathrm{~b})$. The multiplier $\mu^{0}(t)$ [hence also $c^{0}(t)$ ] then depends nontrivially on the current and future variables $\left(y_{t}^{0} \Lambda p_{t}^{0}\right)$, and constraints (25) are not redundant when appended to the constraints of problem (16); i.e. the necessary condition for consistency in Theorem 3.1 fails to hold. As Turnovsky and Brock (1980, p. 201) note, inconsistency then prevails.

\section{Concluding remarks on special cases (a) and (b)}

The special cases (a) and (b) shown in section 4 to be sufficient for consistency are stringent. Since consistency is a neccssary condition for the supportability of first-best optima, finding weaker sufficient conditions for consistency would be desirable.

Unfortunately, no such conditions have been found to date. Indeed, in a companion paper [Tesfatsion (1984b)] it is shown that, for a subclass of the presently considered class of dynamic Walrasian economies, consistency holds if and only if special case (a) or (b) holds. In particular, a first-best optimum is achieved only if special case (a) or (b) holds.

A brief outline of these results will now be given. 
The class of economies considered in Tesfatsion (1984b) is a subclass of the class of dynamic Walrasian economies described in section 2. The basic economy is a one-good two-period model comprising a two-period lived utility-maximizing consumer, a two-period lived profit-maximizing firm, and a government which benevolently attempts to maximize the lifetime utility of the consumer by providing him with a public good in period two. The public good is financed by lump-sum taxes imposed on the consumer and firm in period two. In particular, no consumer choice variables appear in the government's budget constraint.

The economy begins in period one with an initial endowment of the good, controlled by the firm. The firm divides the initial good endowment into consumption and capital portions. The consumption good is sold to the consumer, and the capital is carried over to period two, with zero storagc depreciation. In period two the firm produces additional good using hired labor and capital carry-over. The produced good is divided into an amount paid to government in the form of (real) lump-sum taxes and an amount supplied to the consumer in the form of consumption good. All profits are distributed back to the consumer.

The wage rate and consumption good prices are determined competitively via market clearing conditions. However, markets are incomplete since the consumer cannot borrow or lend. The consumer in period one simply buys consumption good out of profit income. Excess profit income is carried over as savings for old age at a zero real rate of return, irrespective of the marginal productivity of capital in production. The discount factor $\theta$ used by the firm to calculate present-value profits is an exogenously determined timepreference parameter. It does not necessarily equal one, the discount factor which would be obtained using the zero rate of return on consumer savings. In complete-market Walrasian economies, the firm sector is often modelled as an extension of the consumer (shareholder) sector with entirely harmonious objectives. In the presently considered model, the firm takes this form if and only if $\theta$ equals one.

The following results are established in Tesfatsion (1984b) for this class of economies. An economy exhibits consistency if and only if either (a) government policy eliminates all dynamic behavior (capital carry-over as well as consumer savings), so that both the consumer and the firm exhibit perfect myopic foresight locally around the solution path; or (b) the firm's discount factor $\theta$ equals one (the firm is simply an extension of the consumer), so that the consumer has essentially complete structural information. (Recall that consumer choice variables do not appear in the government's budget constraint.) In particular, for each feasible configuration of taste and technology parameters, the corresponding economy achieves its unique first-best optimum only either special case (a) or (b) holds. 


\section{Appendix}

\section{A.1. Technical notes for section 2}

The modifications needed to handle the discrete-time case are as follows. First, expressions of the form $t \geqq \tau$ must now be interpreted to mean $t=\tau$, $\tau+1, \ldots$. Paths thus become discrete sequences. For example, $(c(t))_{t \geqq 0}=$ $\{c(t) \mid t=0,1, \ldots\}$. Second, integrals must be replaced by sums. For example, the integral criterion functions in (12a) and (14a) must be replaced by the sums

$$
\begin{aligned}
& \sum_{t=\tau}^{\infty} u_{t}\left(c^{\tau}(t) \mid f^{\tau}(t), g^{\tau}(t), p^{\tau}(t), x^{\tau}(t)\right), \quad \tau \geqq 0 ; \\
& \sum_{t=\tau}^{\infty} \Pi_{t}\left(f^{\tau}(t) \mid c^{\tau}(t), g^{\tau}(t), p^{\tau}(t), x^{\tau}(t)\right), \quad \tau \geqq 0 .
\end{aligned}
$$

Third, the state differential equations appearing in (12c), (14c), (16c), and elsewhere must be replaced by state difference equations

$$
\begin{aligned}
& x^{\tau}(t+1)=S_{\imath}\left(c^{\tau}(t), f^{\tau}(t), g^{\tau}(t), p^{\tau}(t), x^{\tau}(t)\right), \quad t \geqq \tau ; \\
& x^{\tau}(\tau)=x^{*}(\tau),
\end{aligned}
$$

for each current time $\tau \geqq 0$. Finally, the price derivative $\dot{p}_{+}^{0}(t)$ must be omitted from the market equilibrium conditions appearing in (3) and elsewhere; and the derivatives $\dot{c}_{+}^{0}(t), \dot{f}_{+}^{0}(t), \dot{g}_{+}^{0}(t)$, and $\dot{p}_{+}^{0}(t)$ must be omitted from definition (26) for perfect myopic foresight.

The proofs given below for Theorem 3.1 and Corollaries 4.1 and 4.2 cover both the continuous-time and the discrete-time cases.

\section{A.2. Proof of Theorem 3.1.}

The necessary condition for consistency stated in Theorem 3.1 is established in the main text of section 3. The proof of the sufficiency part of Theorem 3.1 is an immediate consequence of the following two lemmas.

Lemma A.1. For any $s^{\prime}>0$, a sufficient condition for the equilibrium and virtual time-0 state paths $x_{0}^{*}$ and $x_{0}^{0}$ to satisfy

$$
x^{*}(s)=x^{0}(s), \quad s^{\prime} \geqq s \geqq 0,
$$

is

$$
c^{s}\left(s, x^{0}(s)\right)=c^{0}\left(s, x^{0}\right)
$$




$$
\begin{aligned}
& f^{s}\left(s, x^{0}(s)\right)=f^{0}\left(s, x^{0}\right) \\
& g^{s}\left(s, x^{0}(s)\right)=g^{0}\left(s, x^{0}\right) \\
& p^{s}\left(s, x^{0}(s)\right)=p^{0}\left(s, x^{0}\right)
\end{aligned}
$$

for all $s$ satisfying $s^{\prime}>s \geqq 0$.

Proof. Let $s^{\prime}>0$ be given. For any $t \geqq 0$, define

$$
\begin{aligned}
& m_{t}(x(t)) \equiv S_{t}\left(c^{t}(t, x(t)), f^{t}(t, x(t)), g^{t}(t, x(t)), p^{t}(t, x(t)), x(t)\right) \\
& n_{t}(x(t)) \equiv S_{t}\left(c^{0}\left(t, x^{0}\right), f^{0}\left(t, x^{0}\right), g^{0}\left(t, x^{0}\right), p^{0}\left(t, x^{0}\right), x(t)\right)
\end{aligned}
$$

Suppose time is discrete. By definition, $x^{*}(0)=x^{0}(0)=x^{0}$. Assume, as the induction hypothesis, that

$$
x^{*}(s)=x^{0}(s), \quad \bar{s}>s \geqq 0,
$$

for some $\bar{s} \leqq s^{\prime}$. Then, using (A.2) and (A.5), and definitions (11) and (20) for the equilibrium and virtual time- 0 state paths $x_{0}^{*}$ and $x_{0}^{0}$, respectively,

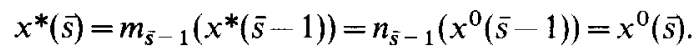

It follows by induction on $\bar{s}$ that (A.1) holds.

Now suppose time is continuous. By assumption (see footnote 8 ), $\boldsymbol{x}_{0}^{*}$ is the unique solution for the differential system

$$
\begin{aligned}
& \dot{x}(t)=m_{t}(x(t)), \quad t \geqq 0 ; \\
& x(0)=x^{0},
\end{aligned}
$$

and $\boldsymbol{x}_{0}^{0}$ is the unique solution for the differential system

$$
\begin{aligned}
& \dot{x}(t)=n_{t}(x(t)), \quad t \geqq 0 \\
& x(0)=x^{0} .
\end{aligned}
$$

However, (A.2) implies that

$$
m_{s}\left(x^{0}(s)\right)=n_{s}\left(x^{0}(s)\right)=\dot{x}^{0}(s), \quad s^{\prime}>s \geqq 0,
$$


hence $\boldsymbol{x}_{0}^{0}$ solves (A.7) over $\left[0, s^{\prime}\right)$. It follows by uniqueness that

$$
x^{*}(s)=x^{0}(s), \quad s^{\prime}>s \geqq 0 ;
$$

hence

$$
\dot{x}^{*}(s)=\dot{x}^{0}(s), \quad s^{\prime}>s>0,
$$

and

$$
x^{*}(\vec{s})=\int_{0}^{\bar{s}} \dot{x}^{*}(s) \mathrm{d} s+x^{*}(0)=\int_{0}^{\bar{s}} \dot{x}^{0}(s) \mathrm{d} s+x^{0}(0)=x^{0}(\vec{s})
$$

for all $\bar{s}$ satisfying $s^{\prime} \geqq \bar{s} \geqq 0$, i.e. (A.1) holds.

Lemma A.2. Suppose the constraints (24h) and (24i) in problem (24) are redundant for every $\tau>0$. Then, for all $t$ and $\tau$ satisfying $t \geqq \tau \geqq 0$, it follows that

$$
\begin{aligned}
& c^{\tau}\left(t, x^{0}(\tau)\right)=c^{0}\left(t, x^{0}\right) \\
& f^{\tau}\left(t, x^{0}(\tau)\right)=f^{0}\left(t, x^{0}\right) \\
& g^{\tau}\left(t, x^{0}(\tau)\right)=g^{0}\left(t, x^{0}\right) \\
& p^{\tau}\left(t, x^{0}(\tau)\right)=p^{0}\left(t, x^{0}\right) .
\end{aligned}
$$

In particular, (A.2) holds for all $s \geqq 0$.

Proof. Clearly (A.10) holds if $\tau=0$. Let $\tau>0$ be given. Under the hypotheses of Lemma A.2, problem (4) is equivalent to problem (24) with the last two constraints $(24 \mathrm{~h})$ and $(24 \mathrm{i})$ deleted. It follows immediately that the $[\tau, \infty)$ continuation $e_{\tau}^{0^{*}}$ of $e_{0}^{0^{*}}$ must then satisfy (A.10).

Combining Lemmas A.1 and A.2, the redundancy of the constraints (24h) and (24i) in problem (24) implies that (A.10) holds with $x^{0}(\tau)=x^{*}(\tau)$ for every $\tau \geqq 0$; i.e. Definition (19) for consistency is satisfied. Q.E.D.

\section{A.3 Proof of Corollary 4.1}

The perfect myopic foresight representations (26) imply that the constraints (24h) and (24i) place no restrictions on $\left(\boldsymbol{c}_{\tau}^{0}, \boldsymbol{f}_{\tau}^{0}, \boldsymbol{g}_{\tau}^{0}, \boldsymbol{p}_{\tau}^{0}\right)$ for any $\tau>0$. Thus, constraints (24h) and (24i) are redundant for problem (24) since $c_{0, \tau}^{0^{*}}, f_{0, \tau}^{0^{*}}, g_{0, \tau}^{0 *}$, and $p_{0, \tau}^{0^{*}}$ then satisfy these constraints by construction for every $\tau \geqq 0$. Q.E.D. 


\section{A.4. Proof of corollary 4.2.}

The proof of Corollary 4.2 follows almost immediately from the following lemma.

Lemma A.3. Consistency prevails if the following two conditions both hold:

(i) Either the time-0 firm choice function $h_{0}^{f}$ exhibts perfect myopic foresight in the sense of (26b), or constraint (4e) in problem (4) is redundant.

(ii) The solution for problem (4) is unchanged if constraint (4d) is replaced by

$$
c^{0}(t) \in \overline{\mathscr{F}}_{i}^{c}\left(f^{0}(t), g^{0}(t), p^{0}(t), x^{0}(t)\right), \quad t \geqq 0,
$$

and government maximizes with respect to $c_{0}^{0}, f_{0}^{0}, g_{0}^{0}$, and $\boldsymbol{p}_{0}^{0}$.

Proof. Condition (i) directly implies that constraint (24i) is redundant for problem (24) for every $\tau \geqq 0$; and condition (ii) implies that constraint (24h) is redundant for problem (24) for every $\tau \geqq 0$, since the requirement that $c^{0}(t)$ be feasible for every $t \geqq 0$ is already fully captured in constraints (24d) and (24g). Consistency then follows from Theorem 3.1.

The proof of Corollary 4.2 now follows by showing that the hypotheses of Lemma A.3 are satisfied, given the hypotheses of Corollary 4.2.

To illustrate, consider the case in which (28) implies (29), (30), and (31). The time- 0 problem (4) for government in the continuous-time case can then equivalently be expressed as the maximization of

$$
\int_{0}^{\infty} u_{t}\left(c^{0}(t) \mid f^{o}(t), g^{o}(t), p^{o}(t), x^{o}(t)\right) \mathrm{d} t
$$

with respect to $c_{0}^{0}, f_{0}^{o}, g_{0}^{0}, p_{0}^{o}$, subject to

$$
\begin{aligned}
& \dot{x}^{0}(t)=S_{t}\left(c^{0}(t), f^{0}(t), g^{0}(t), p^{0}(t), x^{0}(t)\right), \quad t \geqq 0 ; \\
& x^{0}(0)=x^{0} ; \\
& c^{0}(t)=h_{t}^{c}\left(f_{t}^{0}, g_{t}^{0}, p_{t}^{0}, x^{0}(t)\right), \quad t \geqq 0 .
\end{aligned}
$$

(The modifications needed for the discrete-time case are given in section A.1.) However, this problem is in turn equivalent to the maximization of (A.12) subject to constraints (A.11), (A.13), and (A.14), as a two-stage approach to the optimization reveals: i.e. first maximize (A.12) with respect to $c_{0}^{0}$ subject to (A.11), (A.13), and (A.14) conditional on $\left(f_{0}^{0}, g_{0}^{0}, p_{0}^{0}, x^{0}\right)$, which yields (A.15); then maximize the resulting reduced form of (A.12) with respect to 
$\boldsymbol{f}_{0}^{0}, \boldsymbol{g}_{0}^{0}, \boldsymbol{p}_{0}^{0}$ conditional on (A.13) and (A.14). Thus, constraint (4e) in (4) is redundant, and the solution for (4) is unchanged when (4d) is replaced by (A.11). The desired conclusion now follows immediately from Lemma A.3.

The proof for the remaining cases is similar. The two-stage maximization argument still goes through, despite the presence of additional constraints, because these additional constraints by assumption are independent of $c_{0}^{0}$.

Q.E.D.

\section{References}

Brock, W.A., 1974, Money and growth: The case of long-run perfect foresight, International Economic Review 15, 750-777.

Burmeister, E., 1980, Capital theory and dynamics (Cambridge University Press, Cambridge).

Calvo, G.A., 1978, On the time consistency of optimal policy in a monetary economy, Econometrica 46, 1411-1428.

Fischer, S., 1980, Dynamic inconsistency, cooperation, and the benevolent dissembling government, Journal of Economic Dynamics and Control 2, 93-107.

Hillier, B. and J.M. Malcomson, 1984, Dynamic inconsistency, rational expectations and optimal government policy, Econometrica 52, 1437-1451.

Kydland, F.E. and E.C. Prescott, 1980, Dynamic optimal taxation, rational expectations, and optimal control, Journal of Economic Dynamics and Control 2, 79-91.

Lucas, R.E., Jr., 1975, An equilibrium model of the business cycle, Journal of Political Economy $83,1113-1145$.

Lucas, R.E., Jr., 1978, Asset prices in an exchange economy, Econometrica 46, 1429-1445.

Milleron, J.-C., 1972, Theory of value with public goods: A survey, Journal of Economic Theory $5,419-477$.

Nikaido, H., 1968, Convex structures and economic theory (Academic Press, new York).

Saridis, G.N., 1977, Self-organizing control of stochastic systems (Marcel Dekker, New York).

Strotz, R.H., 1956, Myopia and inconsistency in dynamic utility maximization, Review of Economic Studies 23, 165-180.

Tesfatsion, L., 1980, Global and approximate global optimality of myopic economic decisions, Journal of Economic Dynamics and Control 2, 135-160.

Tesfatsion, L., 1984a, The inconsistency of benevolent government economies, Revised Modelling Research Group working paper no. 8222 (Department of Economics, University of Southern California, Los Angeles, CA) April.

Tesfatsion, L., 1984b, Inconsistency with lump-sum taxes and transfers: An example, Modelling Research Group working paper no. 8418, September.

Turnovsky, S.J. and W.A. Brock, 1980, Time consistency and optimal government policies in perfect foresight equilibrium, Journal of Public Economics 13, 183-212. 